\title{
Terminal Penumpang Bandar Udara InTERnasional Dengan Pendekatan Arsitektur Eco Culture Di Daerah ISTimewa YOGYAKARTA
}

\author{
Andi Robbi Cahya, Rachmadi Nugroho, Ahmad Farkhan \\ Program Studi Arsitektur \\ Universitas Sebelas Maret Surakarta \\ Email : andirobbicahya@gmail.com
}

\begin{abstract}
Government of Yogyakarta Province has plans to build a new international airport to replace Adisucipto Airport where is unfit to become an international airport. International airport needs big energy when it build and development of operational time. Yogyakarta is an area rich in culture and reflect every detail culture at the everyday lives of its citizens. Cultural diversity were assimilated and grown, Yogyakarta still steady with Javanese culture until this day. From these issues, the problem that appears is how to design of space systems and building forms that accomodates the activities of airport with Eco Culture Architectural Concept to then be translated into the design of the Passenger Terminal International Airport. The method used in the form of architectural design methods, ranging from data collection and then analyzed based on functional programming, programming performance and architectural analysis. Passenger Terminal International Airport building can be a gateway to and out of Yogyakarta, as well as provide safety, comfort and efficiency. Passenger Terminal International Airport with Eco Culture Architectural can create alternative solutions on an international scale airport design to answer the demands of flight function, the circumstances of the environmental character of the Yogyakarta area and sustainable role in the future.
\end{abstract}

Keywords: Eco Culture Architecture, International Airport, Passenger Terminal.

\section{PENDAHULUAN}

Pemerintah Provinsi Daerah Istimewa Yogyakarta memiliki rencana untuk membangun Bandar Udara Internasional baru untuk menggantikan Bandar Udara Adisutjipto yang tidak layak untuk menjadi bandar udara internasional. Bandar Udara Internasional Adisutjipto sudah menjadi bandar udara internasional sejak 21 Februari 2004. Kebutuhan energi dari suatu Bandar Udara Internasional sangat besar, energi saat pembangunan maupun dari operasional setelah bandar udara internasional jadi akan terus membutuhkan energi.

Data pergerakan lalu lintas udara menyebutkan bahwa kapasitas bandar udara yang didesain hanya untuk 1,05 juta penumpang per tahun ini sudah menampung 2 kali jumlah penumpang sejak tahun 2003. Sejak itu pergerakan penumpang Bandar Udara Adisutjipto terus tumbuh rata-rata $11 \%$. Pergerakan penumpang pada tahun 2014 penumpang domestik dan internasional di Bandar Udara Internasional Adisutjipto mencapai 6,3 juta penumpang. (Kementrian
Perhubungan, 2014). Tingkat penggunaan terminal saat ini hampir mencapai $600 \%$ atau jumlah penumpang yang ada sudah enam kali lipat dari kapasitas terminal yang ada.

$$
\text { Daerah Istimewa Yogyakarta }
$$
merupakan daerah yang kaya akan budaya serta adat istiadat ini mencerminkan setiap detail kebudayaannya pada kehidupan warganya sehari-hari. Keanekaragaman budaya yang sudah terasimilasi dan berkembang, Daerah Istimewa Yogyakarta masih kental dengan budaya dan adat istiadat Jawa yang masih dijaga hingga saat ini. Inilah yang mendorong banyak wisatawan baik lokal maupun internasional untuk berkunjung ke Daerah istimewa Yogyakarta.

Bangunan Terminal Penumpang Bandar Udara Internasional yang direncanakan menjadi gerbang menuju dan keluar Daerah Istimewa Yogyakarta dan sekitarnya, serta memberikan rasa aman, nyaman dan efisien. Terminal penumpang bandar udara ini diharapkan dapat menciptakan alternatif pemecahan dari suatu desain Bandar Udara berskala Internasional yang menjawab tuntutan 
fungsi penerbangan, situasi dan kondisi karakter lingkungan Daerah Istimewa Yogyakarta yang berwawasan lingkungan serta kesinambungan perannya di masa yang akan datang.

\section{METODE}

1. Mengenali Konsep Arsitektur Eco Culture yang berhubungan dengan bandar udara

2. Mengidentifikasi penggunaan bandar udara, di antaranya pelaku kegiatan, jenis kegiatan, pola kegiatan, sifat kegiatan

3. Menganalisis persyaratan pemilihan tapak, persyaratan kebutuhan ruang, persyaratan besaran ruang dan program ruang, serta penggunaan selubung

4. Menganalisis bentuk massa bangunan disesuaikan dengan bentuk tapak dan arah pandang pengunjung.

5. Membuat denah berdasarkan analisis yang telah dilakukan

6. Membuat tampilan massa dan ruang sesuai dengan Konsep Arsitektur Eco Culture

\section{ANALISIS}

\subsection{Analisis Peruangan}

Ruang-ruang dalam terminal dibagi menurut kelompok kegiatannya menjadi seperti pada Tabel 1 berikut:

Tabel 1.Kebutuhan Ruang

\begin{tabular}{|l|l|}
\hline \multicolumn{1}{|c|}{$\begin{array}{c}\text { KEBERANGKAT- } \\
\text { AN }\end{array}$} & KEDATANGAN \\
\hline $\begin{array}{l}\text { Pelataran } \\
\text { Keberangkatan }\end{array}$ & $\begin{array}{l}\text { Area Break Down } \\
\text { Bagasi }\end{array}$ \\
\hline Pelataran Check-in & System Baggage \\
\hline Counter Inquiry & $\begin{array}{l}\text { Area Pengambilan } \\
\text { Bagasi }\end{array}$ \\
\hline Counter Reservation & Ruang Bagasi \\
\hline Counter Check-in & $\begin{array}{l}\text { Sistem Transfer } \\
\text { Bagasi }\end{array}$ \\
\hline $\begin{array}{l}\text { Kantor Maskapai } \\
\text { Penerbangan }\end{array}$ & $\begin{array}{l}\text { Unit Penyimpanan } \\
\text { Bagasi }\end{array}$ \\
\hline System Baggage & Ruang Kedatangan \\
\hline Area Make Up Bagasi & $\begin{array}{l}\text { Pemeriksaan } \\
\text { Kedatangan }\end{array}$ \\
\hline Pemeriksaan Imigrasi & $\begin{array}{l}\text { Pemeriksaan } \\
\text { Imigrasi }\end{array}$ \\
\hline Cek Keamanan & Duty Free Shop \\
\hline Check Customs & Check Customs \\
\hline Duty Free Shop & $\begin{array}{l}\text { Area Visitor } \\
\text { Greeter }\end{array}$ \\
\hline
\end{tabular}

\begin{tabular}{|l|l|}
\hline $\begin{array}{l}\text { R. Tunggu } \\
\text { Keberangkatan }\end{array}$ & Counter Inquiry \\
\hline $\begin{array}{l}\text { Pintu Masuk Hold } \\
\text { Room }\end{array}$ & $\begin{array}{l}\text { Pelataran } \\
\text { Keberangkatan }\end{array}$ \\
\hline Gate Check & R. Tunggu Transit \\
\hline Ruang Tunggu VIP & Proses Transfer \\
\hline
\end{tabular}

\subsection{Analisis Lokasi}

Menentukan posisi yang strategis dalam memilih lokasi peletakan terminal penumpang

\subsubsection{Tujuan}

Lokasi yang sesuai untuk terminal bandar udara.

\subsubsection{Dasar Pertimbangan}

Posisi tapak strategis untuk proses menaikkan dan menurunkan penumpang secara cepat dan efisien, mudah dicapai, luasan tapak dapat menampung seluruh kebutuhan ruang yang direncanakan.

\subsubsection{Proses Analisis}

Posisi tapak terminal penumpang bandar udara dekat dengan posisi landasan pacu dan landasan hubung. Posisi Terminal Penumpang dengan konfigurasi seperti itu akan membuat pesawat mudah, cepat dan efisien untuk sampai ke wilayah apron yang berhubungan langsung dengan Terminal Penumpang seperti pada Gambar 1 berikut:

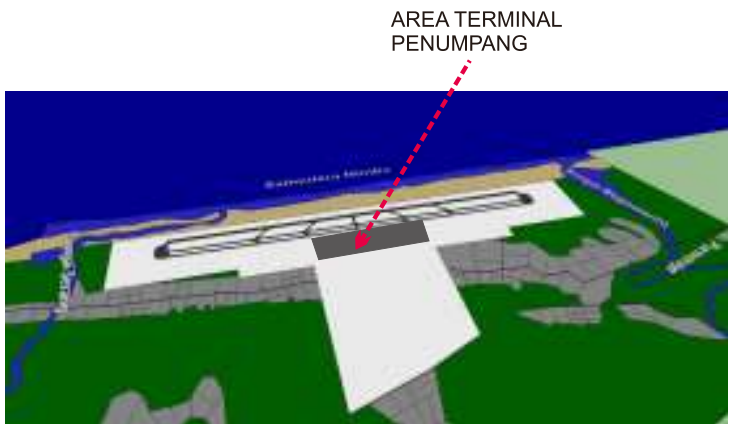

Gambar 1. Posisi Terminal Penumpang Terhadap Landasan Pacu

\subsection{Analisis Pemintakatan (Penzoningan)}

Pemintakatan berdasarkan sifat kegiatan dan keadaan dalam tapak dilakukan sebagai acuan dalam penataan peruangan, namun tetap memperhatikan modul-modul struktur yang telah diterapkan.

\subsubsection{Tujuan}

Mintakat (zoning) berdasarkan sifat kegiatan dan keadaan pada tapak. 


\subsubsection{Dasar pertimbangan}

Analisis peruangan, analisis pengolahan tapak.

\subsubsection{Proses Analisis}

Persyaratan ruang, berdasarkan tingkat hubungan dengan pengguna seperti pada Gambar 2 berikut:

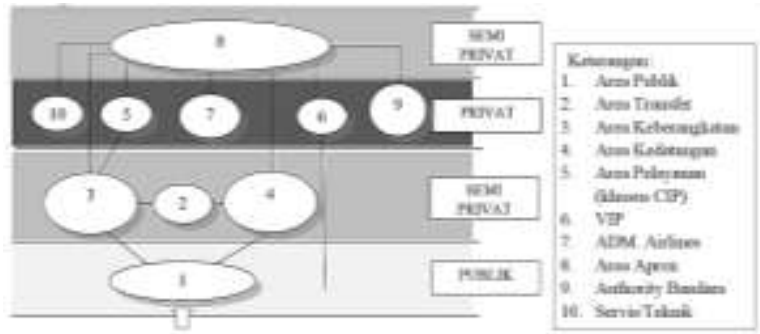

Gambar 2. Pemintakatan Peruangan Terminal Penumpang Bandar udara

\subsection{Analisis Klimatologis}

\subsubsection{Tujuan}

Kondisi yang nyaman di dalam bangunan dari pemecahahan masalah akibat iklim yang terkait seperti matahari, angin, gelombang laut dan hujan dan potensi iklim dapat dimanfaatkan potensinya untuk bandar udara di Yogyakarta dan pengaruhnya terhadap pertimbangan desain.

\subsubsection{Dasar Pertimbangan}

Arah edar matahari, tingkat kemiringan matahari, arah edar tiupan angin, energi gelombang laut dan curah hujan

\subsubsection{Proses analisis}

Matahari dapat dimanfaatkan sinarnya untuk diubah menjadi energi listrik. Penggunaan panel surya dapat memanfaatkan energi dari matahari untuk dikonversi menjadi energi listrik. Panel surya diletakkan pada atap bangunan dengan kemiringan $\pm 7.55^{\circ}$ diarah utara untuk memaksimalkan masuknya sinar matahari. Dengan potensi iklim berupa lama penyinaran matahari yang cukup tinggi setiap harinya, penggunaan panel surya merupakan sebuah langkah ekologis yang tepat, seperti pada Gambar 3 berikut:

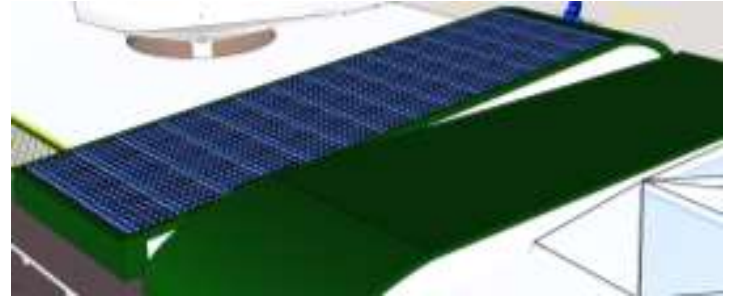

Gambar 3. Pemanfaatan Energi Matahari dengan Menggunakan Panel Surya

Energi angin merupakan energi yang selalu tersedia sepanjang waktu (siang dan malam), mudah didapatkan, dan tidak menimbulkan polusi.

Pada area bandar udara memiliki batas ketinggian minimum untuk penggunaan kincir angin. Kincir angin ada dua jenis, sumbu horizontal dan sumbu vertikal. Sumbu horizontal membutuhkan ketinggian kincir yang tinggi $+80 \mathrm{~m}$, maka penggunaannya tidak dapat diaplikasikan ke dalam area bandar udara.

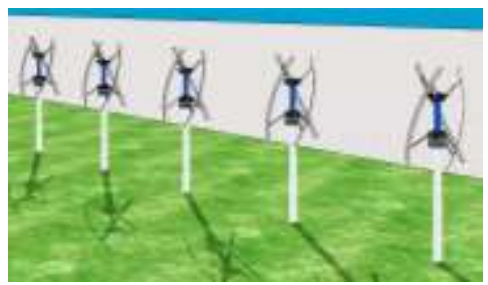

Gambar 4. Pemanfaatan Angin dengan Menggunakan Turbin Omni-directional

Gambar 4 merupakan turbin angin sumbu vertikal tidak memerlukan kecepatan angin yang tinggi dan teratur untuk beroperasi seperti pada sumbu horizontal, sehingga turbin angin sumbu vertikal dapat diletakkan pada ketinggian yang lebih rendah. Keuntungan turbin omni-directional sumbu vertikal adalah kemampuan yang dimiliki membuatnya lebih cocok untuk diaplikasikan pada area Terminal Penumpang Bandar Udara Internasional

Gelombang laut di sebelah Selatan Pulau Jawa yang memiliki karakteristik ombak yang besar dapat menyebabkan abrasi dan semakin lama akan menyebabkan terganggunya kestabilan dan fungsi bangunan. Mengurangi dampak abrasi dapat menggunakan cara penanaman bakau dan penggunaan pemecah ombak, tetapi bakau tidak mampu hidup karena terlalu kuat gelombang dari Samudera Hindia, 
maka penggunaan pemecah gelombang lebih tepat, seperti pada Gambar 5 berikut:

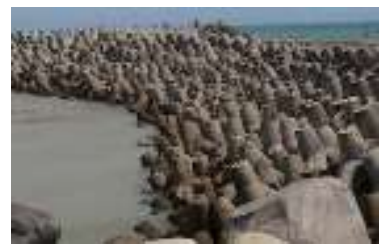

Gambar 5. Penggunaan Pemecah Ombak untuk Mengurangi Dampak Abrasi

Gelombang laut yang besar dapat dimanfaatkan dengan mengubah energinya menjadi energi listrik yaitu dengan menggunakan oscillating water coloumn. Cara kerja alat ini yaitu gelombang masuk melalui lubang bawah permukaan ke dalam ruang dengan udara yang terjebak di atas. Gelombang menyebabkan air yang berada di dalam kolom air bergerak ke atas dan ke bawah, mendorong udara yang terjebak ke dalam turbin listrik yang menghasilkan gerak turbin terus-menerus seperti pada Gambar 6 berikut:

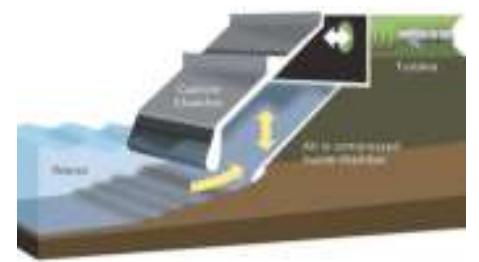

Gambar 6. Penggunaan Oscillating Water Coloumn untuk Memanfaatkan Potensi dari Gelombang Laut

Hujan di daerah tapak hampir terjadi sepanjang tahun, bangunan juga harus tanggap terhadap kondisi hujan yang terjadi agar bangunan tetap kokoh berdiri.

Atap bangunan Terminal Penumpang Bandar Udara Internasional dibuat miring agar air hujan dapat mengalir dari atap, serta bangunan diberi tritisan agar dinding tidak langsung terkena hujan, seperti pada Gambar 7 berikut:

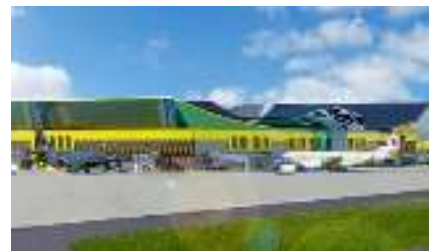

Gambar 7. Atap Bangunan Dibuat Miring dan Terdapat Tritisan
Air hujan juga dapat menaikkan muka preatik air sumur apabila diresapkan dalam tanah, dapat pula dimanfaatkan langsung dengan penggunaan rain water catcher pada Terminal Penumpang Bandar Udara untuk menampung air hujan lalu dapat digunakan untuk penyiram tanaman dan toilet seperti pada Gambar 8 berikut:

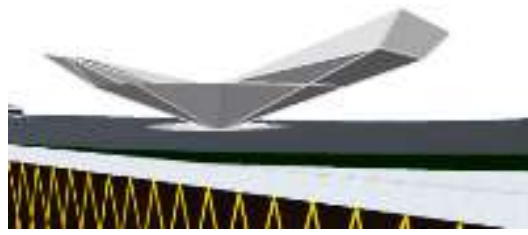

Gambar 8. Penggunaan Rain Water Catcher untuk Memanfaatkan Air Hujan

Pembangunan bandar udara dengan upaya konservasi air tanah ini penting, karena kebutuhan air bersih bagi bandar udara sangat besar.

\subsection{Analisis View dan Orientasi 3.5.1 Tujuan}

Zonasi tapak dan orientasi bangunan yang dapat memaksimalkan tampilan bangunan dan tapak dengan konsep Arsitektur Eco Culture.

\subsubsection{Dasar Pertimbangan}

Sudut pandang dari dalam maupun luar tapak, jangkauan pandang pengamat dari luar lokasi terutama dilihat dari angkasa, dari sisi udara bandar udara maupun dari kendaraan bergerak.

\subsubsection{Proses Analisis}

Analisis pada view dan orientasi Terminal Penumpang Bandar Udara Internasional di Daerah Istimewa Yogyakarta akan mengedepankan analisis view ke dalam tapak daripada view ke luar tapak dan view di dalam tapak yaitu view kegiatan di sisi airside.

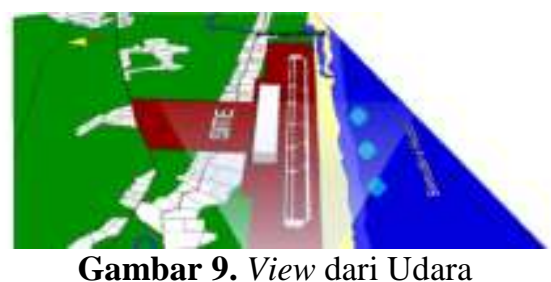

Gambar 9 view dari udara akan terlihat semua area tapak termasuk area pantai dan Samudera Hindia yang juga akan menambah nilai positif view apabila menuju bandar udara ini, maka orientasi pengolahan tapak perlu menampilkan ke arah udara. 
Budaya Jawa, wayang, gunungan memiliki makna sebagai pintu gerbang, atau memasuki suatu wilayah. Pengolahan tapak menerapkan bentuk gunungan untuk menandakan bahwa akan memasuki Daerah Istimewa Yogyakarta seperti pada Gambar 10 berikut:

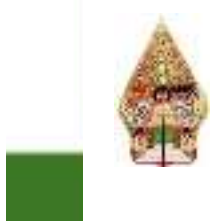

Gambar 10. Pengolahan Tapak dengan Penerapan Bentuk Gunungan

\subsection{Analisis Bentuk dan Tampilan Bangunan}

\subsubsection{Tujuan}

Bentuk dan tampilan bangunan yang sesuai dengan kriteria perancangan Terminal Penumpang Bandar Udara Internasional dengan konsep Arsitektur Eco Culture.

\subsubsection{Dasar Pertimbangan}

1. Efisiensi ruang

2. Fungsi bangunan sebagai Terminal Penumpang Bandar Udara Internasional yang menuntut kelancaran pergerakan

3. Kesesuaian dengan kondisi tapak

4. Fleksibel dan mudah dikembangkan

\subsubsection{Proses Analisis}

Daerah Istimewa Yogyakarta merupakan sebuah provinsi yang kaya akan budaya serta adat istiadat ini mencerminkan setiap detail kebudayaannya pada kehidupan warganya sehari-hari. Selain keanekaragaman budaya yang sudah terasimilasi dan berkembang, Daerah Istimewa Yogyakarta juga masih kental dengan budaya dan adat istiadat Jawa yang masih dijaga hingga saat ini. Daerah Istimewa Yogyakarta masih menyandang sebagai daerah istimewa karena memiliki sistem pemerintah dan tata ruang wilayah yang khas dan harus tetap dijaga dan dilestarikan.

Keraton Ngayogyakarta Hadiningrat atau Keraton Yogyakarta memiliki tata ruang dasar kota tua Yogyakarta berporoskan garis lurus utara ke selatan, poros Gunung MerapiKeraton Yogyakarta-Laut Selatan, ibarat "tritunggal" yang satu dengan lainnya saling menopang hingga ketiganya tetap ada. Poros tersebut memiliki 9 Gerbang dan yang paling selatan adalah Plengkung Nirbaya, sekarang dikenal dengan nama Plengkung Gadhing.

Gubahan massa pada Terminal Penumpang Bandar Udara Internasional berangkat dari bentuk tapak yang memanjang. Penyesuaian yang berangkat dari bentuk tapak akan dapat memaksimalkan lahan dan mengoptimalkan kebutuhan ruang di dalamnya. Bentuk dari Plengkung Nirbaya, seperti pada Gambar 11 akan sesuai dengan bentuk tapak selain itu bandar udara yang direncanakan juga merupakan akses menuju Daerah Istimewa Yogyakarta melalui sisi selatan yang sama dengan fungsi Plengkung Nirbaya yaitu gerbang masuk selatan.
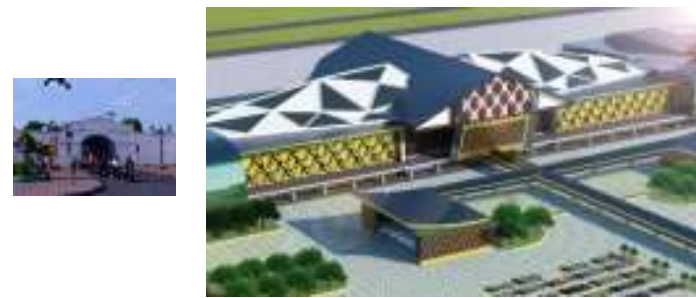

Gambar 11. Gubahan Masa Dipengaruhi oleh Bentuk Gerbang Selatan Yogyakarta

Penggunaan secondary skin pada sisi utara Terminal Penumpang Bandar Udara Internasional untuk mengurangi intensitas cahaya yang masuk dengan bentuk pola batik parang rusak seperti pada Gambar 12, terinspirasi dari ombak laut selatan menjadi inspirasi pola batik, motif ini diciptakan oleh Panembahan Senopati yang terinspirasi oleh ombak yang tak lelah menghantam karang pantai.
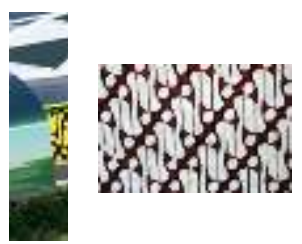

Gambar 12. Penggunaan Secondary Skin dengan Bentuk Parang Rusak

\subsection{Analisis Tampilan Ruang Dalam 3.7.1 Tujuan}


Bentuk ruang dalam yang menampilkan kebudayaan Jawa dan penggunaan bahan material yang berwawasan lingkungan.

\subsubsection{Dasar Pertimbangan}

1. Unsur-unsur budaya yang ingin ditampilkan

2. Jenis kegiatan yang diwadahi

3. Kenyamanan pengguna

4. Nilai estetika

5. Penggunaan material yang ramah lingkungan.

\subsubsection{Proses Analisis}

Ruang dalam adalah sesuatu penggambaran dari konsep bangunan yang dirasakan dan bersentuhan langsung dengan si pengguna bangunan. Pemilihan warna dan jenis materialnya dipilih menyesuaikan dengan konsep dan fungsi bangunan.

Terminal Penumpang Bandar Udara Internasional akan mengusung Konsep Arsitektur Eco Culture yang berbalut tradisional Jawa pada ruang dalam bangunannya. Bahan material kayu dan material serat alam melimpah di wilayah sekitar tapak. Bahan material tersebut merupakan bahan material yang mudah untuk didaur ulang yang sesuai dengan konsep yang diusung yaitu Konsep Arsitektur Eco Culture. Penggunaan motif-motif Kebudayaan Jawa akan diekspos pada bagian ruang dalamagar menguatkan ciri khas Terminal Penumpang Bandar Udara Internasional di Daerah Istimewa Yogyakarta. Memasukan nuansa taman luar ke dalam gedung terminal merupakan ide untuk memperindah estetika ruang dalam sekaligus untuk kepentingan ekologis pada bangunan terminal itu sendiri.

Terdapat berbagai ragam hias pada kebudayaan Jawa. Ragam hias pada Tabel 2 merupakan ragam hias yang dapat diaplikasikan pada ruang dalam bangunan yang dapat menunjang Konsep Arsitektur Eco Culture beserta maknanya.

Tabel 2. Ragam Hias Flora pada Bangunan Jawa

\begin{tabular}{|c|c|c|c|}
\hline Nama & Wujud & Letak & Arti \\
\hline 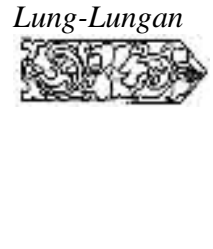 & $\begin{array}{l}\text { Tumbuhan } \\
\text { menjalar } \\
\text { dibuat } \\
\text { stilisasi } \\
\text { seperti } \\
\text { tanaman } \\
\text { surga, }\end{array}$ & $\begin{array}{l}\text { Umumnya } \\
\text { terdapat di } \\
\text { bagian } \\
\text { balok } \\
\text { rangka } \\
\text { atap, } \\
\text { pamidanga }\end{array}$ & $\begin{array}{l}\text { Estetika } \\
\text { dan wingit }\end{array}$ \\
\hline
\end{tabular}

\begin{tabular}{|c|c|c|c|}
\hline Nama & Wujud & Letak & Arti \\
\hline & $\begin{array}{l}\text { dengan } \\
\text { daun, } \\
\text { bunga, dan } \\
\text { buah } \\
\text { (merah, } \\
\text { hijau, } \\
\text { kuning, } \\
\text { biru, ungu) }\end{array}$ & $\begin{array}{l}n \quad \text { (bawah } \\
\text { brunjung), } \\
\text { tebeng } \\
\text { pintu, } \\
\text { jendela, } \\
\text { dan patang } \\
\text { aring }\end{array}$ & \\
\hline $\begin{array}{l}\text { Saton } \\
\text { Sygse- }\end{array}$ & $\begin{array}{l}\text { Bentuk } \\
\text { persegi } \\
\text { dengan } \\
\text { hiasan daun } \\
\text { dan bunga. } \\
\text { Warna } \\
\text { hijau, } \\
\text { merah, } \\
\text { emas. }\end{array}$ & $\begin{array}{l}\text { Ragam } \\
\text { hias } \\
\text { terletak di } \\
\text { balok } \\
\text { rangka } \\
\text { atap, tiang } \\
\text { bangunan } \\
\text { atas } \\
\text { bawah, } \\
\text { tebeng } \\
\text { pintu. }\end{array}$ & $\begin{array}{l}\text { Keindah- } \\
\text { an }\end{array}$ \\
\hline Wajikan & $\begin{array}{l}\text { Berbentuk } \\
\text { belah } \\
\text { ketupat. } \\
\text { Berisi daun } \\
\text { atau bunga. } \\
\text { Warna yang } \\
\text { kontras }\end{array}$ & $\begin{array}{l}\text { Ragam } \\
\text { hias } \\
\text { terletak di } \\
\text { tengah } \\
\text { tiang atau } \\
\text { pada } \\
\text { persilang- } \\
\text { an balok } \\
\text { agar } \\
\text { bangunan. }\end{array}$ & $\begin{array}{l}\text { Wajikan } \\
\text { di } \\
\text { samping } \\
\text { sebagai } \\
\text { estetika } \\
\text { juga } \\
\text { wingit. }\end{array}$ \\
\hline 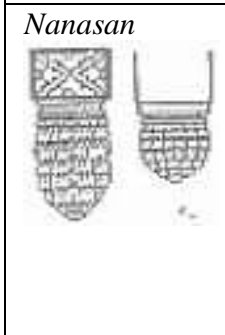 & $\begin{array}{l}\text { Mirip } \\
\text { nanas, } \\
\text { omah } \\
\text { tawon, atau } \\
\text { prit gantil. } \\
\text { Warna } \\
\text { sesuai } \\
\text { dengan } \\
\text { bangunan. }\end{array}$ & & $\begin{array}{l}\text { Keindah- } \\
\text { an dan } \\
\text { usaha } \\
\text { keras } \\
\text { untuk } \\
\text { mendapat- } \\
\text { kan } \\
\text { kebahagia } \\
\text {-an. }\end{array}$ \\
\hline BAacapan & $\begin{array}{l}\text { Deretan } \\
\text { segitiga } \\
\text { sama } \\
\text { tinggi. } \\
\text { Polos atau } \\
\text { berisi lung- } \\
\text { lungan. } \\
\text { Warna } \\
\text { emas } \\
\text { dengan } \\
\text { dasar hijau } \\
\text { atau merah } \\
\text { tua. }\end{array}$ & $\begin{array}{l}\text { Pangkal } \\
\text { dan ujung } \\
\text { balok } \\
\text { kerangka } \\
\text { bangunan. }\end{array}$ & $\begin{array}{l}\text { Sinar } \\
\text { matahari } \\
\text { atau } \\
\text { sorotan } \\
\text { berarti } \\
\text { kecerahan } \\
\text { dan } \\
\text { keagung- } \\
\text { an. }\end{array}$ \\
\hline 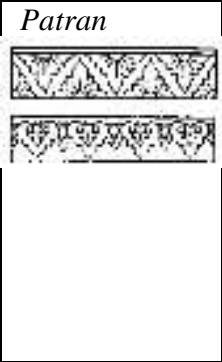 & $\begin{array}{l}\text { Dari kata } \\
\text { patra berarti } \\
\text { daun. } \\
\text { Berbentuk } \\
\text { daun } \\
\text { berderet. }\end{array}$ & $\begin{array}{l}\text { Tepian } \\
\text { atau hiasan } \\
\text { pada } \\
\text { bidang } \\
\text { datar kecil } \\
\text { dan } \\
\text { meman- } \\
\text { jang di } \\
\text { bagian } \\
\text { balok }\end{array}$ & $\begin{array}{l}\text { Keindaha } \\
\mathrm{n} \text { dan } \\
\text { kesempur } \\
\text { naan }\end{array}$ \\
\hline
\end{tabular}




\begin{tabular}{|c|c|c|c|}
\hline Nama & Wujud & Letak & Arti \\
\hline & & $\begin{array}{l}\text { rangka } \\
\text { bangunan. }\end{array}$ & \\
\hline Padma & $\begin{array}{l}\text { Bunga } \\
\text { teratai } \\
\text { berwarna } \\
\text { merah }\end{array}$ & $\begin{array}{l}\text { Terletak di } \\
\text { alas tiang } \\
\text { (umpak) }\end{array}$ & $\begin{array}{l}\text { Estetika } \\
\text { dan } \\
\text { kesucian } \\
(\text { padma }), \\
\text { kokoh, } \\
\text { kuat }\end{array}$ \\
\hline
\end{tabular}

\section{KESIMPULAN (KONSEP DESAIN)}

Konsep rancangan Terminal Penumpang Bandar Udara Internasional yang mengacu pada pembentukan dan penataan elemen arsitektur untuk menciptakan sebuah wadah yang berkaitan dengan kegiatan kebandarudaraan dengan pendekatan desain yaitu Arsitektur Eco Culture, akan menciptakan sebuah Terminal Penumpang Bandar Udara Internasional menjadi sebuah gerbang menuju dan keluar Daerah Istimewa Yogyakarta dan sekitarnya, serta memberikan rasa aman, nyaman dan efisien. Terminal Penumpang Bandar Udara Internasional di Daerah Istimewa Yogyakarta dapat menciptakan alternatif pemecahan dari suatu desain Bandar Udara berskala Internasional yang memiliki karakter budaya Jawa yang menjawab tuntutan fungsi penerbangan, situasi dan kondisi karakter lingkungan Daerah Istimewa Yogyakarta yang berwawasan lingkungan serta kesinambungan perannya di masa yang akan datang.

Hasil analisis serta hasil korelasi dari beberapa data di atas, maka diperoleh hasil berupa rancangan Terminal Penumpang Bandar Udara Internasional dengan Pendekatan Arsitektur Eco Culture di Daerah Istimewa Yogyakarta sebagai berikut.

Nama Bandar udara : New Yogyakarta International Airport

Lokasi : Kulon progo

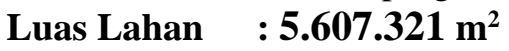

Luas Bangunan $\quad: \mathbf{1 9 8 . 4 3 7} \mathrm{m}^{2}$

Daya Tampung : 30juta orang per tahun

Daerah Istimewa Yogyakarta merupakan daerah yang kaya akan budaya serta adat istiadat ini mencerminkan setiap detail kebudayaannya pada kehidupan warganya sehari-hari. Budaya Jawa adalah budaya yang berasal dari Jawa dan dianut oleh masyarakat Jawa khususnya di Jawa Tengah, Daerah istimewa Yogyakarta dan Jawa Timur. Budaya Jawa secara garis besar dapat dibagi menjadi 3 yaitu budaya Banyumasan, budaya Jawa Tengah-Daerah Istimewa Yogyakarta dan budaya Jawa Timur. Budaya Jawa menjunjung tinggi kesopanan dan kesederhanaan. Kebudayaan Jawa ini tidak hanya menampilkan nilai-nilai estetika, namun budaya ini mengedepankan nilai-nilai toleransi, keselarasan, keserasian dan keseimbangan dalam kehidupan seharihari.

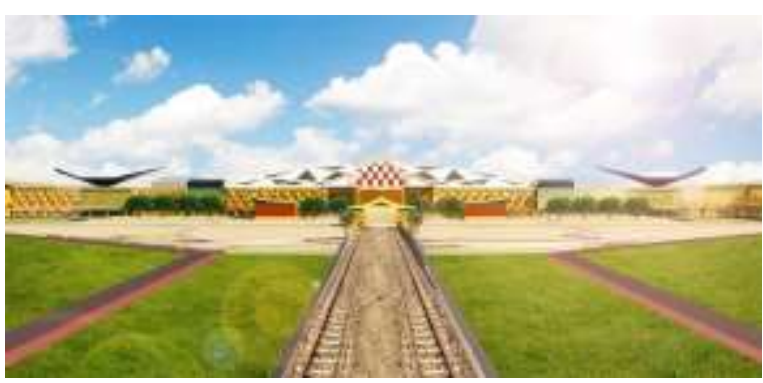

Gambar 13. Perspektif Eksterior dari Depan

Gambar 13 terlihat bangunan Terminal Penumpang Bandar Udara Internasional memiliki penampilan yang memberikan gambaran tentang budaya Jawa. Penggunaan material-material ramah lingkungan dan penggunaan warna hangat serta rekayasa bentuk yang memiliki kesan hangat atau menerima dengan ramah kepada para tamu yang berkunjung ke Yogyakarta serta selaras, serasi dan seimbang dalam kehidupan sehari-hari.

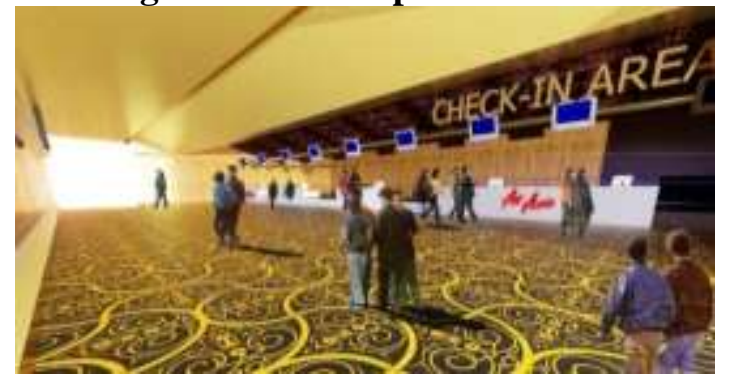

Gambar 14. Perspektif Interior Ruang Check-in 


\section{REFERENSI}

Kementrian Perhubungan, 2014, Buku Informasi Geospasial Kementrian Perhubungan, Jakarta: GIS

Sukawi, 2008, Ekologi Arsitektur : Menuju Perancangan Arsitektur Hemat Energi dan Berkelanjutan, Semarang :

Gambar 15. Perspektif Interior Ruang Klaim Bagasi Universitas Diponegoro

Gambar 14 dan 15 terlihat bagaimana sebuah ruang check-in dan ruang klaim bagasi masih menggunakan warna dominan kuning dan coklat serta pola-pola etnik untuk menampilkan budaya Jawa yang hangat serta menerima dengan ramah pengguna terminal penumpang yang akan menuju maupun meninggalkan Daerah Istimewa Yogyakarta.

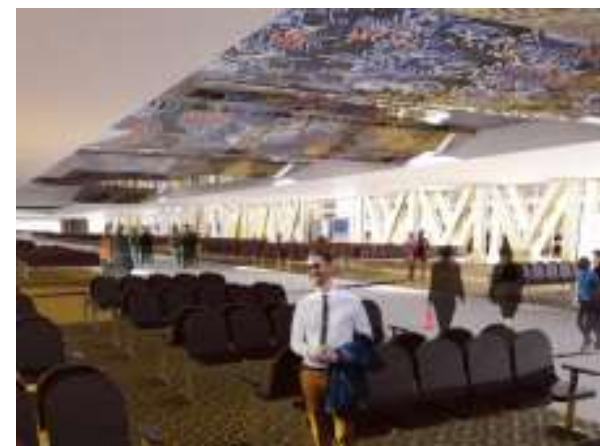

Gambar 16. Perspektif Interior Ruang Tunggu Keberangkatan

Gambar 16 terlihat bagaimana sebuah ruang tunggu keberangkatan menampilkan atau mengekspos batik pada plafon dengan bantuan cahaya alami yang diambil dari skylight. Budaya Jawa merupakan kebudayaan yang kaya akan hasil karya, rasa dan cipta salah satunya adalah batik. 